\title{
ADRENAL DISORDERS: II. CONGENITAL VIRILIZING ADRENAL HYPERPLASIA*
}

\author{
BY \\ LAWSON WILKINS \\ From the Department of Paediatrics, Johns Hopkins School of Medicine, Baltimore
}

Today I shall discuss congenital virilizing adrenal hyperplasia. This is a fascinating disorder, partly because it can be so well controlled therapeutically, and partly because it is an experiment of nature, not producible in the laboratory, which has helped the understanding of the normal biosynthesis and physiology of adrenocortical hormones. It is also one of the best understood of the genetically determined enzymatic defects.

Before considering the fundamental aetiology and mechanism of this disorder which is so entirely different from Cushing's syndrome, let us review briefly the clinical manifestations and the results of treatment.

\section{Clinical Manifestations and Diagnosis}

There are three different types of virilizing adrenal hyperplasia causing (1) simple virilism, (2) virilism with hypertension and (3) virilism with tendency to sodium loss. Their relative incidence in our clinic is shown in Table 1. Each of these types may be due to a different specific defect of enzymes concerned in the synthesis of adrenal hormone, since in each family in which the disorder occurs all the children affected have the same type of the disease. The Table suggests, at first glance, that about four times more females than males are affected. Childs (1960), however, believes that this ratio may be based on the fact that the disease is more apt to pass undiagnosed in the male. Eliminating the so-called 'index cases' which present in the clinic, he found that the affected sibs of those cases have an approximately equal sex distribution as shown in Table 2.

The progressive virilization, which is the common and most conspicuous manifestation in all cases, is due to excessive production of adrenal androgens. Likewise the rapid growth, increased musculature and accelerated epiphyseal development are caused by the protein-anabolic action of androgen. The exact nature of the adrenal androgens in the circu-

* Part 2 of the Leonard Parsons Memorial Lectures, 1961. Part 1 appeared in this Journal, Volume 37 , page 1 lation is not known, but their end metabolites in the 17-ketosteroid fraction of the urine are well known. When the disease occurs in the female foetus it causes masculinization of the external genitalia consisting of phallic enlargement either with or without labioscrotal fusion. In some cases the urogenital sinus extends to the tip of the phallus so that the patient could readily be mistaken for a cryptorchid male. On the other hand, the female pseudohermaphrodites have normal female development of their genital ducts and gonads so that they have uterus, tubes and ovaries. However, the diagnosis of virilizing adrenal hyperplasia cannot be based on these anatomical findings alone because masculinization of the female foetus may be caused by giving androgens or certain synthetic progestogens to gestating mothers. To establish the diagnosis it is necessary to demonstrate that the patient is secreting excessive amounts of androgen. Fortunately, as early as two or three weeks after birth the urinary 17-ketosteroids are definitely elevated in respect to the patient's age. As shown in Table 3,

TABLE 1

RELATIVE INCIDENCE OF DIFFERENT TYPES OF VIRILIZING ADRENAL HYPERPLASIA

\begin{tabular}{cc|c|c|c|c}
\hline & $\begin{array}{c}\text { Virilism } \\
\text { Alone }\end{array}$ & $\begin{array}{c}\text { Salt- } \\
\text { losing }\end{array}$ & $\begin{array}{c}\text { Hyper- } \\
\text { tensive }\end{array}$ & Total \\
\hline Females & $\ldots$ & $55^{*}$ & 34 & 5 & 94 \\
Males & $\cdots$ & 13 & 10 & 2 & 25 \\
\hline Total & $\ldots$ & 68 & 44 & 7 & 119 \\
\hline
\end{tabular}

* Nine raised as males.

TABle 2

CORRECTED SEX RATIOS OF PATIENTS WITH VIRILIZING ADRENAL HYPERPLASIA

\begin{tabular}{|c|c|c|c|c|c|}
\hline & & Males & Females & Totals & $\begin{array}{c}\text { Sex Ratio } \\
\text { M./F. }\end{array}$ \\
\hline $\begin{array}{l}\text { Index cases } \\
\text { Affected sibs }\end{array}$ & $\begin{array}{l}\cdots \\
\cdots\end{array}$ & $\begin{array}{l}30 \\
14\end{array}$ & $\begin{array}{l}84 \\
18\end{array}$ & $\begin{array}{r}114 \\
32\end{array}$ & $\begin{array}{l}0 \cdot 36 \\
0 \cdot 78\end{array}$ \\
\hline Total $\ldots$ & . & 44 & 102 & 146 & 0.43 \\
\hline
\end{tabular}


TABLE 3

LEVELS OF 17-KETOSTEROIDS IN PATIENTS WITH VIRILIZING ADRENAL HYPERPLASIA COMPARED TO NORMALS OF SAME AGE

\begin{tabular}{c|c|c|c}
\hline $\begin{array}{c}\text { Age } \\
\text { (years) }\end{array}$ & $\begin{array}{c}\text { No. of } \\
\text { Patients }\end{array}$ & $\begin{array}{c}17 \text { K.S. } \\
\text { (mg.) }\end{array}$ & $\begin{array}{c}\text { Normal 17 K.S. } \\
\text { (mg.) }\end{array}$ \\
\hline 0-6 mths & 19 & $1-10$ & $<0.5$ \\
$7-12$ mths & 3 & $3-10$ & $<0.5$ \\
$1-5$ & 28 & $4-30$ & $<1.0$ \\
$6-9$ & 9 & $11-40$ & $<2.0$ \\
$10-15$ & 6 & $16-50$ & $<10.0$ \\
$>15$ & 12 & $21-80$ & $<15.0$ \\
\hline
\end{tabular}

they increase with advancing years. Later there is progressive virilization with precocious sexual hair, excessive growth and musculature and advanced epiphyseal development.

Males with the adrenogenital syndrome are distinguished from those with other types of sexual precocity by the fact that their urinary 17-ketosteroids are elevated above the normal adolescent or adult levels, while their testes usually remain small and immature.

Patients with the hypertensive type of adrenal hyperplasia differ from those with simple virilism only in the occurrence of elevated blood pressure which responds to cortisone therapy and recurs when it is withdrawn.

Infants with the salt-losing type of adrenal hyper-

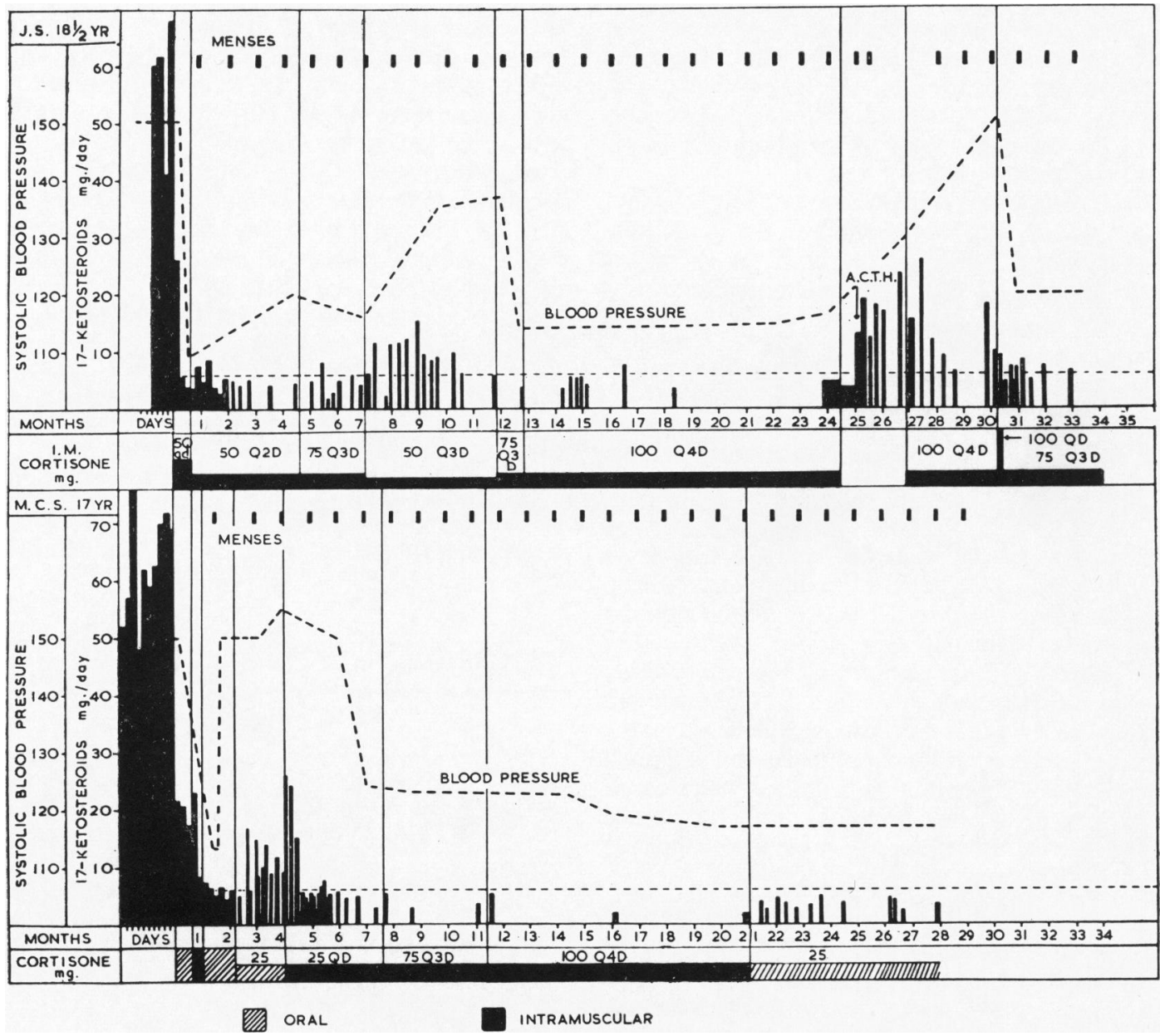

Fig. 1.-Method of determining minimal maintenance dose of cortisone on the basis of the 17-KS output (from Wilkins, 1961). In the upper case, $50 \mathrm{mg}$. of intramuscular cortisone daily reduced on 17-KS from 60 to $6 \mathrm{mg}$. per day. Suppression was maintained $50 \mathrm{mg}$. every second day and $75 \mathrm{mg}$. every third day or $100 \mathrm{mg}$. every fourth day, but decrease of dose to $50 \mathrm{mg}$. every third day permitted 17-KS to rise.

In the lower case $50 \mathrm{mg}$. daily of oral cortisone given in divided doses failed to reduce the 17-KS below $20 \mathrm{mg}$. per day, while $50 \mathrm{mg}$. daily intramuscularly caused a fall to $6 \mathrm{mg}$. per day. Subsequently $50 \mathrm{mg}$. crally maintained this suppression, but 25 mg. orally was inadequate. 


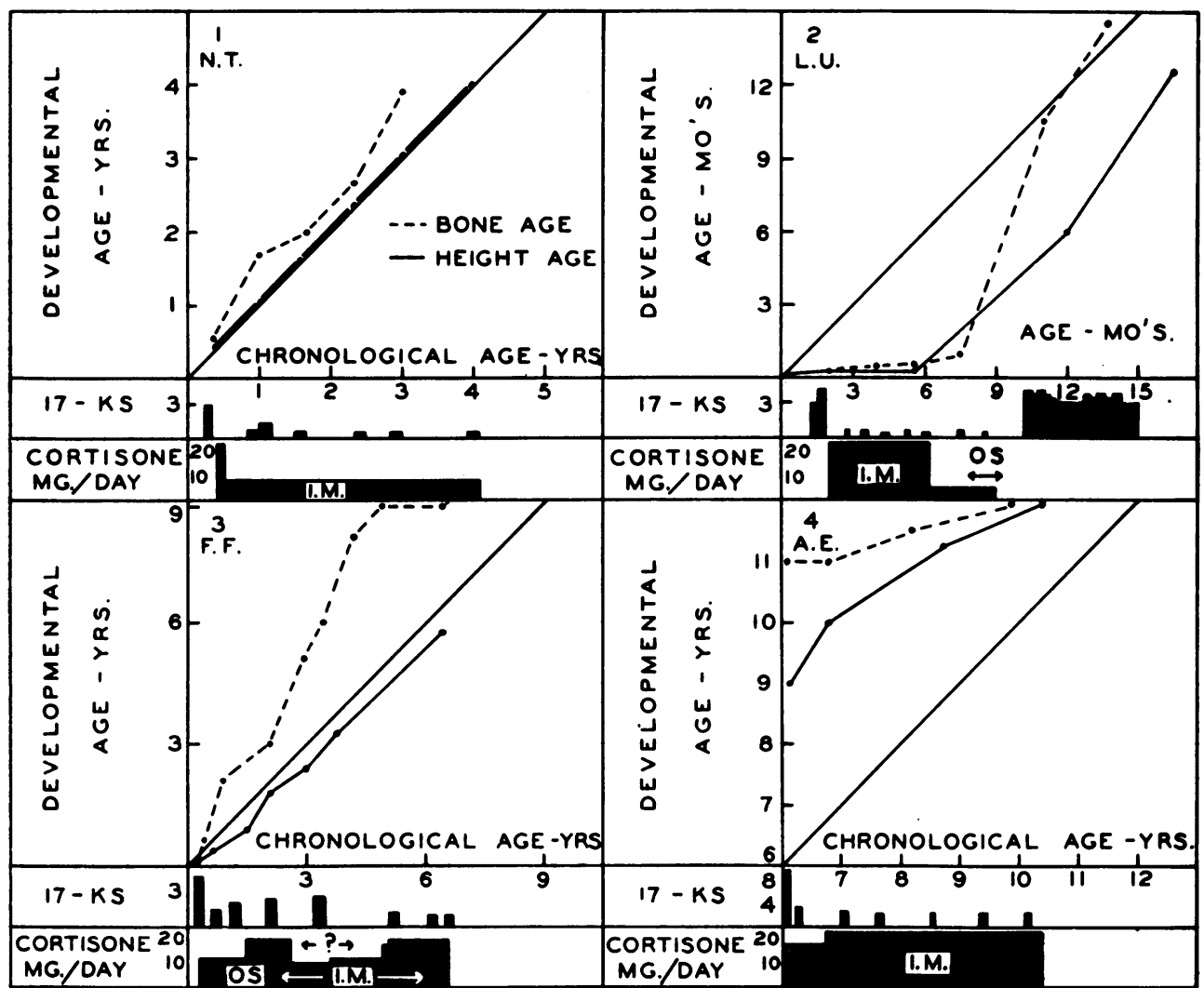

Fig. 2.-Rates of growth and osseous development as a guide to proper dosage of cortisone (from Wilkins, 1961). If androgenic activity of adrenal is not adequately suppressed, the 17-KS are elevated and there is accelerated growth and osseous development. If excessive cortisone is given there is retardation of growth and development.

plasia usually have anorexia, vomiting and weight loss within the first two or three weeks of life. Unless treated properly, they become severely dehydrated, develop circulatory collapse, and die rapidly. When salt-losing symptoms occur in a female pseudohermaphrodite, the true nature of the disorder is readily suspected, but in males death may occur before macrogenitosomia is obvious. The condition should be suspected when there is a history of siblings who have died with similar symptoms. The diagnosis depends upon finding low serum $\mathrm{Na}$ and $\mathrm{CO}_{2}$ and, more importantly, elevated serum $\mathrm{K}$. To prove, however, that the $\mathrm{Na}$ loss is due to virilizing adrenal hyperplasia and not to some other adrenal disorder, it is necessary to demonstrate that the urinary $17-\mathrm{KS}$ are elevated.

\section{Treatment}

The principle of treatment is to supress adrenal activity by supplying the physiological requirements for adrenal hormone with a cortisol-like steroid, thus preventing the formation of precursors which have androgenic and sometimes hypertensive effects. In infants with the $\mathrm{Na}$-losing type, treatment with desoxycorticosterone or some other Na-retaining hormone, together with increased intake of $\mathrm{NaCl}$, are usually necessary, in addition to cortisone. Initially, in order to bring about rapid suppression of the abnormal adrenals, relatively large doses of cortisone are given. After this it is necessary to determine the minimal dose required to maintain adequate suppression by following the output of 17-ketosteroids as shown in Fig. 1. In growing children it is equally important to regulate long-range treatment according to the rates of growth and osseous development as shown in Fig. 2. If adequate suppression is not obtained the osseous development continues to advance rapidly and will lead eventually to premature epiphyseal fusion. If excessive treatment is given, growth and development will be unduly retarded. With proper dosage, 
TABLE 4

INITIAL AND MAINTENANCE DOSES OF CORTISONE EFFECTIVE IN TREATMENT OF VIRILIZING ADRENAL HYPERPLASIA

\begin{tabular}{|c|c|c|c|c|c|c|c|}
\hline \multirow{3}{*}{$\begin{array}{c}\text { Age } \\
\text { (years) }\end{array}$} & \multirow{2}{*}{\multicolumn{2}{|c|}{$\begin{array}{l}\text { 17-Ketosteroids } \\
\text { (mg./day) }\end{array}$}} & \multicolumn{5}{|c|}{ Dose of Cortisone (mg.) } \\
\hline & & & \multirow{2}{*}{$\begin{array}{c}\text { Initial } \\
\text { I.M. }\end{array}$} & \multicolumn{4}{|c|}{ Maintenance } \\
\hline & $\begin{array}{c}\text { Before } \\
\text { Treatment }\end{array}$ & $\begin{array}{l}\text { Under } \\
\text { Treatment }\end{array}$ & & \multicolumn{2}{|c|}{ Intramuscular } & \multicolumn{2}{|l|}{ Oral } \\
\hline $\begin{array}{l}>6 \\
2-6 \\
<2\end{array}$ & $\begin{array}{c}20-80 \\
8-20 \\
2-8\end{array}$ & $\begin{array}{c}4-6 \\
2-4 \\
0 \cdot 5-1 \cdot 5\end{array}$ & $\begin{array}{l}100 \text { Q.D. } \\
50 \text { Q.D. } \\
25 \text { Q.D. }\end{array}$ & $\begin{array}{l}75 / 3 D \\
50-75 / 3 D \\
25-37 \cdot 5 / 3 D\end{array}$ & $\begin{aligned} & \text { per day } \\
= & 25 \\
= & 16-25 \\
= & 8-12\end{aligned}$ & $\begin{array}{l}25 \times(2 \text { or } 3) \\
12 \cdot 5-25 \times(2 \text { or } 3) \\
5-10 \times(3 \text { or } 4)\end{array}$ & $\begin{aligned} & \text { per day } \\
= & 50-75 \\
= & 25-50 \\
= & 15-20\end{aligned}$ \\
\hline
\end{tabular}

growth proceeds normally and abnormal metabolic changes do not occur.

Table 4 shows the initial and maintenance doses of cortisone which we have found effective. It is most important, however, to realize the difference between intramuscular and oral medication, which depends upon the rates of absorption of the steroid used. When cortisone is given intramuscularly it is absorbed slowly and has an action extending over three or four days. After a depot has been established by giving daily injections for five to 10 days, doses spaced at intervals of three or four days will maintain a uniform level of suppression. Some workers have had satisfactory results with still longer-acting depot preparations such as the trimethyl-acetate of prednisone. On the other hand, cortisone when given orally is rapidly absorbed and is effective for a few hours only. Accordingly, to maintain uniform suppression of the adrenals it is necessary to give it three to four times daily and approximately two or three times the daily intramuscular dose is required.

It should be emphasized most strongly that whenever the adrenals have been suppressed by steroids they are unable to respond normally to the increased needs for hydrocortisone in conditions of stress, such as an acute infection, trauma or surgical operation. The parents and attending physician must be warned that under these circumstances greatly increased amounts of cortisone must be given. If there is time to prepare for an operation, the additional cortisone may be given intramuscularly beginning three days previously. In an emergency it should be given orally or intravenously because of its more rapid action by these routes.

Although some infants with milder degrees of the Na-losing type of virilizing adrenal hyperplasia when treated with cortisone can be maintained in electrolyte balance by merely adding 2 to $5 \mathrm{~g}$. of $\mathrm{NaCl}$ to their daily diet, most patients need, in addition, a Na-retaining hormone and are safer with it. We still prefer the implantation of two to five $125-\mathrm{mg}$. pellets of desoxycorticosterone acetate (DOCA), adjusting the salt intake according to requirements. The pellets are gradually absorbed over periods of nine to 12 months. At the end of this time most of our patients have not required reimplantation of pellets and some have now gone 10 to 11 years without difficulties, provided they continue cortisone therapy and are permitted extra salt according to their desires. We have shown, however, that these patients who seem to have lost their Na-losing tendency are still unable to conserve sodium and get into trouble when salt intake is restricted. Instead of implanting pellets, some workers prefer to give injections of long-acting trimethyl-acetate of desoxycorticosterone at intervals of three or four weeks. We have treated some of our patients with the addition of 9-alpha-fluorohydrocortisone given orally in daily doses of 0.05 to $0.1 \mathrm{mg}$.

Time does not permit me to discuss the newer, more potent, orally administered steroids. Suffice it to say they have no advantage over cortisone and cost more, and some such as triamcinolone and dexamethasone have so many toxic side-effects or are so potent that they are dangerous.

\section{Results of Treatment}

We have now treated 102 patients with cortisone or related steroids for periods ranging from a few months to 11 years (Table 5). The earlier in life that treatment is begun the more completely is the advance of virilism prevented and accordingly the less dramatic are the results. When patients are treated properly before the age of 2 years they simply grow and develop like normal children and all virilization and hirsutism are prevented. Surgical correction of the external genitalia has generally been carried out on females before the age of 2 or 3 years. When treatment is begun later progressive virilization and hirsutism and accelerated epiphyseal development are checked. However, if the epiphyseal development is already far advanced, some stunting of the ultimate height attained will result. The time at which adolescent sex development, along 
either normal female or male lines, begins depends upon the patient's general developmental level as indicated by the 'bone age' rather than the chronological age. If the patient's bone age is already at the adolescent level before treatment is begun, adolescence occurs with great rapidity, ovulatory menstrual cycles develop in females and fertility is possible. In males, testicular maturation and spermatogenesis occur. Although there are many more interesting points in regard to treatment which I would like to discuss, let us now turn to the pathogenesis and genetics of this disorder.

\section{Pathogenesis}

The fact that these large abnormal adrenals were so readily controlled by small physiological doses of cortisone was very striking. Bartter, Albright, Forbes, Leaf, Dempsey and Carroll (1951) were the first to suggest that in the adrenogenital syndrome the ability of the adrenals to synthesize hydrocortisone might be impaired and Jailer (1953) confirmed this by showing that A.C.T.H.caused little increase in its output. We (Wilkins, Gardner, Crigler, Silverman and Migeon, 1952) illustrated this concept with a diagram (Fig. 3), indicating that there was a partial defect in the production of glucogenic and possibly Na-retaining hormones and the formation of abnormal amounts of androgenic and oestrogenic steroids. To compensate for the relative deficiency of hydrocortisone, the activity of the adrenals was whipped up by increased secretion of pituitary A.C.T.H. The latter was found to be increased in the blood by Sydnor and colleagues (Sydnor, Kelley, Raile, Ely and Sayers, 1953). The fact that the concentration of cortisol in the plasma and the output of its metabolites tetrahydro-F (THF) and tetrahydro-E (THE) in the urine did not increase to a normal extent with the administration of exogenous A.C.T.H. might, of course, have been due to the fact that the adrenals were working already under maximal A.C.T.H. stimulation. However, the urine was shown to contain relatively large amounts of abnormal steroids, such as pregnanetriol, not found in normal individuals, and these were increased by A.C.T.H., indicating that the adrenals were responsive (Bongiovanni, Eberlein and Cara, 1954). The question was raised also as to whether abnormal metabolites were due to an abnormality in the hepatic degradation of adrenal steroids or whether they were the expected degradation products of certain precursors of hydrocortisone which accumulated in excess because of a block in its synthesis. Recent work confirms the latter hypothesis as does the fact that these compounds disappear when the adrenals are suppressed with
TABLE 5

AGES OF PATIENTS AT BEGINNING OF CORTISONE THERAPY, AND DURATION OF TREATMENT

\begin{tabular}{|c|c|c|c|}
\hline Age & Females & Males & Total \\
\hline $\begin{array}{r}< \\
2-10 \\
11-18 \\
19-49\end{array}$ & $\begin{array}{r}40 \\
22 \\
9 \\
10\end{array}$ & $\begin{array}{r}6 \\
15\end{array}$ & $\begin{array}{r}46 \\
37 \\
9 \\
10\end{array}$ \\
\hline Total & 81 & 21 & 102 \\
\hline \multicolumn{2}{|c|}{$\begin{array}{c}\text { Duration of Treatment } \\
\text { (years) }\end{array}$} & \multicolumn{2}{|c|}{ Cases } \\
\hline \multicolumn{2}{|c|}{$\begin{array}{l}5-11 \\
2-5 \\
<2\end{array}$} & \multicolumn{2}{|c|}{$\begin{array}{l}60 \\
28 \\
14\end{array}$} \\
\hline \multicolumn{2}{|c|}{ Total ... } & \multicolumn{2}{|c|}{102} \\
\hline
\end{tabular}

cortisone. It still remains to determine more specifically the actual defects of steroidogenesis.

I discussed yesterday the general principles of synthesis and metabolic degradation of steroidal hormones. These depend largely upon changes in the A-ring and the groups attached at $\mathrm{C}_{3}$ (see Fig. 1 of Wilkins, 1961). Thus the structure of each metabolite tells us the steroid from which it was

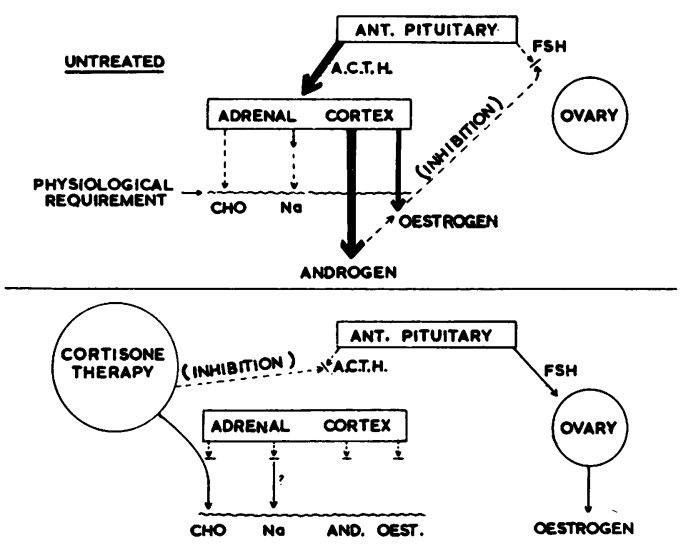

FIG. 3.-The mechanism of virilizing adrenal hyperplasia and its correction with cortisone (from Wilkins et al., 1952).

There is impaired ability of the adrenal to synthesize glucogenic hormones (CHO) and sometimes Na-retaining hormone ( $\mathrm{Na})$ and excessive production of androgenic and oestrogenic steroids. The oestrogens produce no effect on the sex organs because they are antagonized by excessive androgen. In order to meet the physiological requirements for hydrocortisone there is increased secretion of A.C.T.H. The high concentration of circulating sex hormones inhibits the secretion of pituitary gonadotropins (F.S.H. and L.H.) so that the gonad remains immature and does not secrete When cortisone is given in amounts to meet the physiological requirements, A.C.T.H. is inhibited and the abnormal adrenal is put at rest except that it may continue to secrete aldosterone $(\mathrm{Na})$. When the adrenal androgens and oestrogens are suppressed, pituitary gonadotrophin can be secreted to cause maturation of the gonads and the secretion of normal sex hormones. 


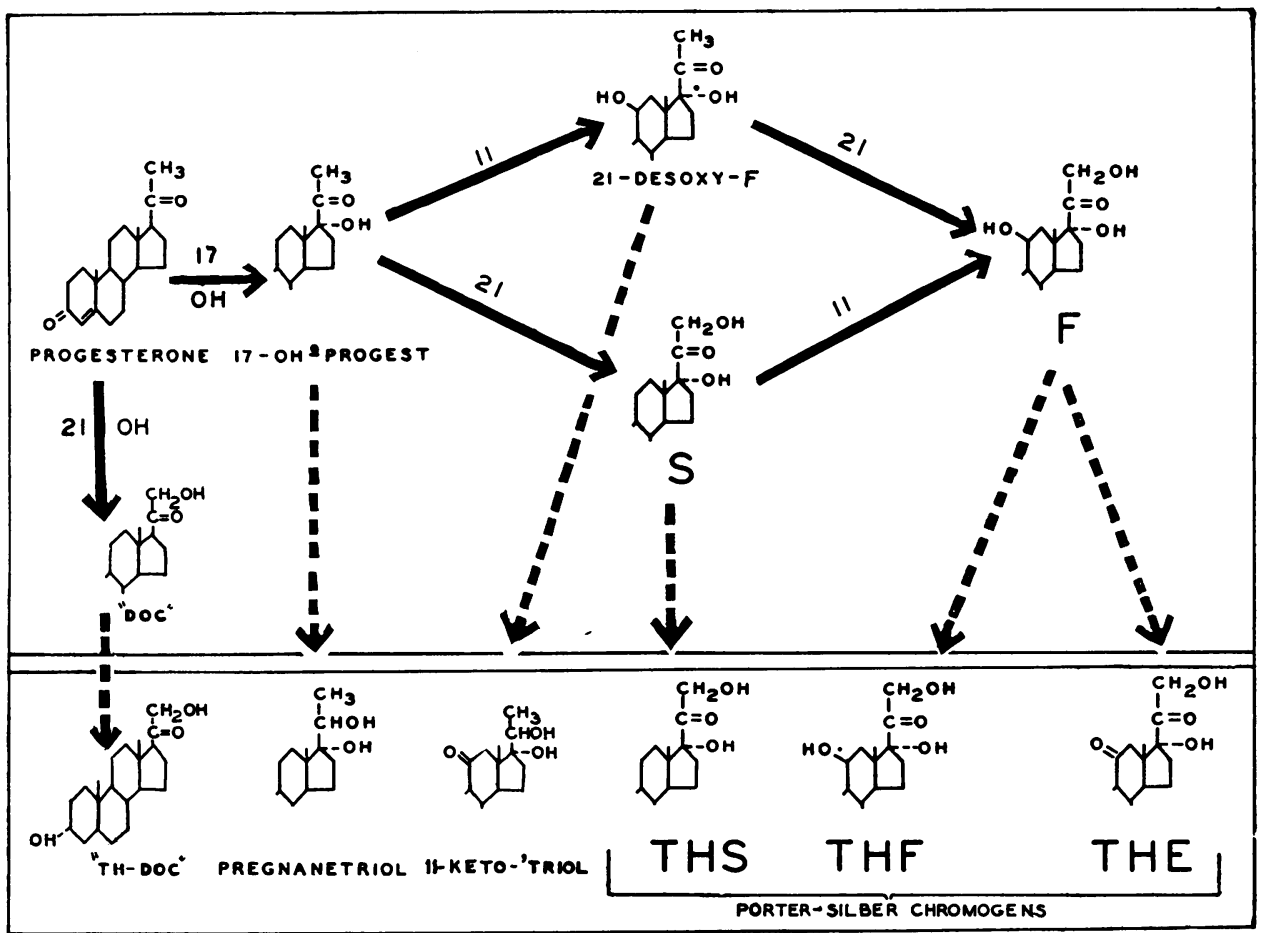

FIG. 4.-Pathway of biosynthesis of hydrocortisone showing intermediary precursors and the 21-carbon urinary metabolites derived from them.

derived. Fig. 4 is a simplified scheme showing the synthesis of hydrocortisone from progesterone and the urinary 21-carbon metabolite derived from each of the intermediary precursors. The solid arrows indicate the hydroxylations which occur at the 17 , 11 and 21 carbon atoms. The dotted arrows indicate the corresponding end-metabolite derived from each of the precursors of compound $F$ (hydrocortisone). Some of the intermediary compounds in the formation of these metabolites have been purposely omitted. From this chart, one can predict which metabolites one would expect to find when there is a defect of $C_{21}$ hydroxylation, of $C_{11}$ hydroxylation or of both of these hydroxylations.

Less is known about the synthesis of the 19carbon steroids or androgens of the adrenal or the derivation of the 19-carbon metabolites-the 17ketosteroids. Fig. 5 in the lower section shows the probable synthesis of $\Delta_{4}$ androstenedione and $11 \beta$-hydroxyandrostenedione from dehydroepiandrosterone. The 19-carbon urinary metabolites (17ketosteroids) which are principally androsterone and etiocholanolone and their 11-oxy derivatives are shown in the middle section. As indicated by the dotted arrows a portion of these metabolites can be derived from the 21-carbon steroids (upper line) as well as from the 19-carbon steroids (lower line). However, the 21-carbon steroids make only a minor contribution, probably not over 5 to $10 \%$ of the total 19-carbon metabolites.

The C-21 Hydroxylation Defect. The simple virilizing form of adrenal hyperplasia is due primarily to a defect in 21-hydroxylation as shown in Fig. 6. With this defect the precursors of cortisol, 17-OH-progesterone and 21-desoxy-F, are increased, giving rise to increased urinary output of both pregnanetriol and 11-oxypregnanetriol. There is also increased excretion of the 17-ketosteroids and the 11-oxy-17-ketosteroids.

The C-11 Hydroxylation Defect. Eberlein and Bongiovanni (1955) showed that in patients with the hypertensive form of virilizing adrenal hyperplasia the defect is one of 11-hydroxylation rather than 21hydroxylation. As shown in Fig. 7 this gives rise to an entirely different pattern of urinary metabolites. Compound $\mathbf{S}$ is formed and tetrahydro-S (THS) is excreted in large amounts. Pregnanetriol is formed but 11-oxygenated preg- 


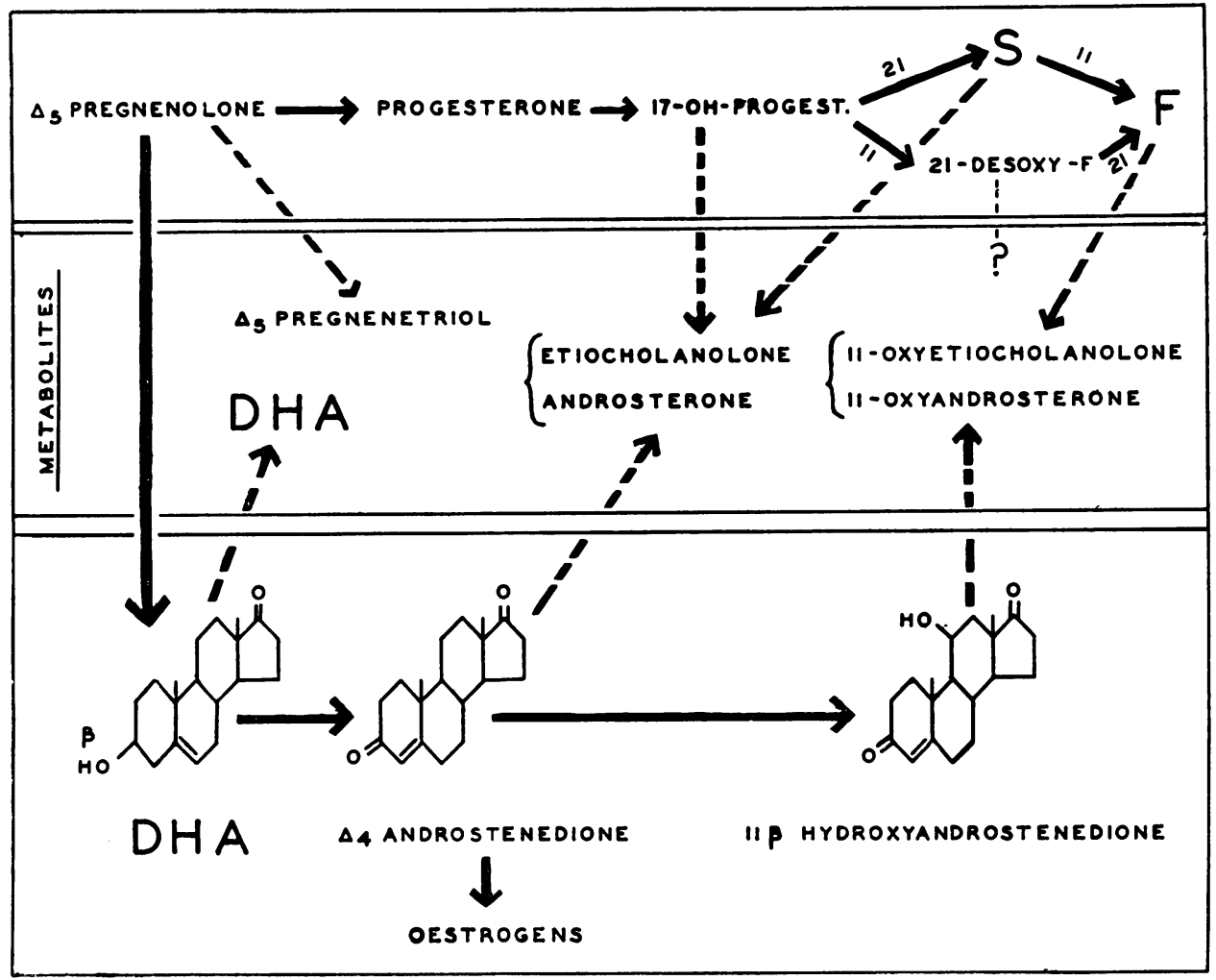

FIG. 5.-Urinary 19-carbon metabolites showing their derivation from both 19-carbon and 21-carbon steroids.

nanetriol is missing. The 11-oxygenated 17-ketosteroids are also absent. Likewise, DOC and tetrahydro-DOC are formed (these are not shown on this chart, but are derived from progesterone

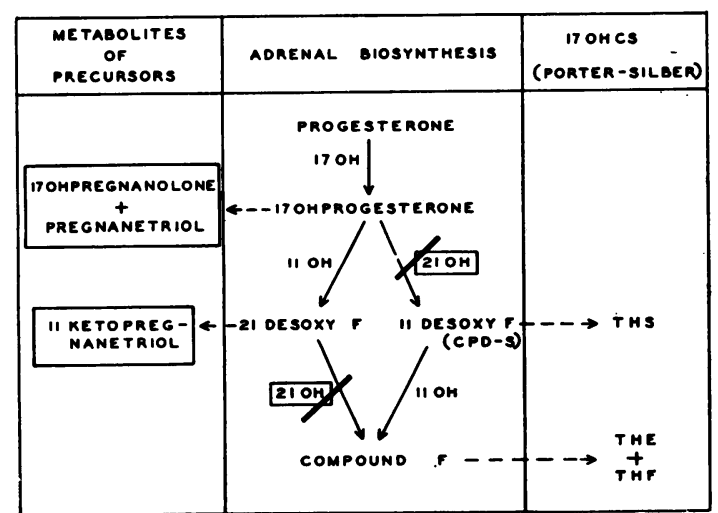

FIG. 6.-21-hydroxylase defect in simple virilizing and Na-losing types of congenital adrenal hyperplasia.

Note that 17-OH-pregnanolone, pregnanetriol and 11-ketopregnanetriol are increased, while THE, THF and THS are decreased. before hydroxylation at $\mathrm{C}_{17}$ ). The $\mathrm{DOC}$ is believed to be the cause of hypertension which disappears when the adrenal is suppressed with cortisone. However, a few patients with virilizing adrenal

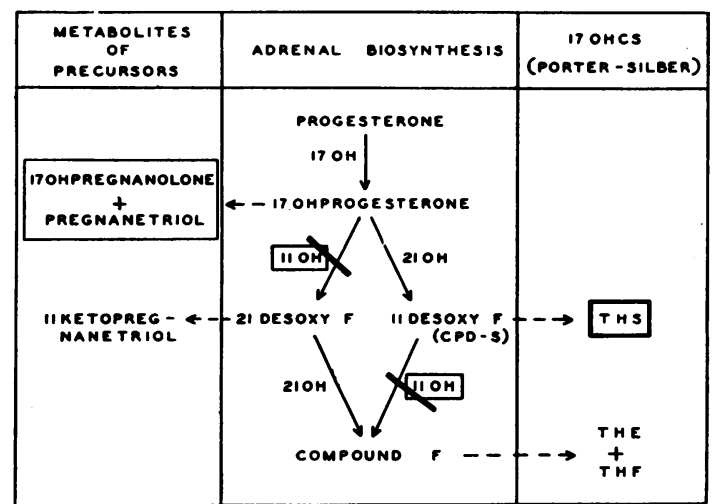

Fig. 7.-11-hydroxylase defect in hypertensive type of virilizing adrenal hyperplasia.

Note that 17-OH-pregnanolone, pregnanetriol and THS are increased, while THE and THF are decreased. 


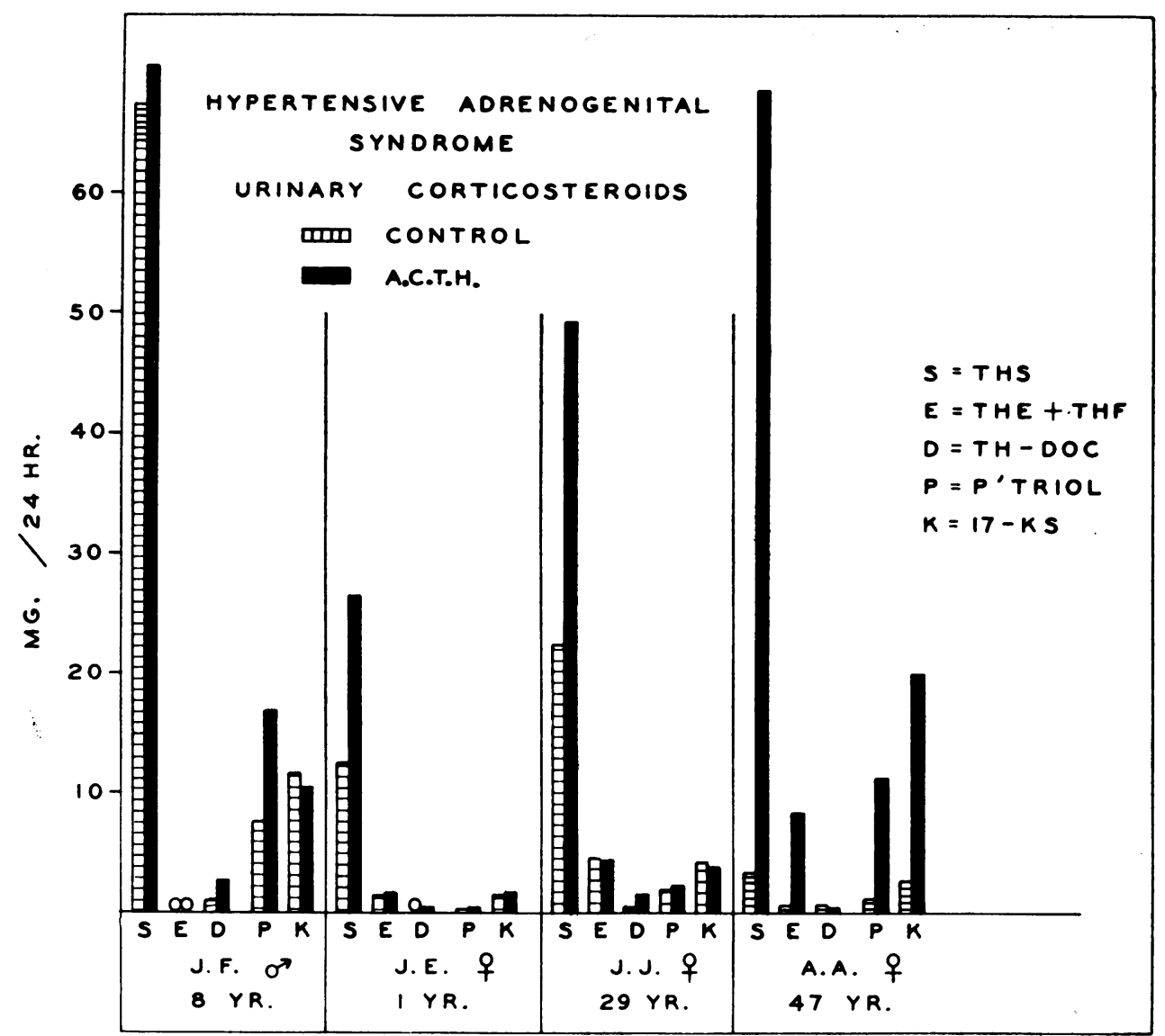

FIG. 8.-Variations of urinary steroidal patterns in individual cases of the hypertensive type of virilizing adrenal hyperplasia (from Green al., 1960).

hyperplasia caused by the 11-hydroxylation defect have not had hypertension.*

These enzyme defects are probably never entirely complete and vary somewhat in degree from one patient to another. This is illustrated by the urinary steroidal patterns of some patients studied in our laboratory by Green, Migeon and Wilkins (1960), shown in Figs 8 and 9. Although there are minor differences between the patients of each group, it is obvious that there is a very striking difference between the patients who are hypertensive and those who are not.

* Since the lecture was given, Bongiovanni (1961) has published proof of the existence of a third enzymatic defect which causes virilizing adrenal hyperplasia. This is a deficiency of $3 \beta$-hydroxydehydrogenase. It causes decreased production of cortisol and its metabolites, decrease of pregnane compounds (pregnanetriol, etc.) with marked increase of the $\Delta_{5}-3 \beta-\mathrm{OH}$ compounds such as $\Delta_{5}$ pregnenolone, $\Delta_{5}$ pregnenetriol and dehydroepiandrosterone $\left(\Delta_{5}\right.$ androstene-3 $\beta$-ol-17-one).
The Na-losing Type of Adrenal Hyperplasia. As shown in Fig. 9, these patients have the $C_{21}$ rather than the $C_{11}$ hydroxylation defect. Bongiovanni and Eberlein (1958) and Eberlein and Bongiovanni (1960) have shown that patients with the salt-losing type of adrenal hyperplasia have a greater impairment in the formation of hydrocortisone than do those with the simple virilizing type, and our own observations agree with this. They suggest that the difference between the two types is a quantitative rather than a qualitative one and that hydrocortisone may be necessary or 'permissive' for aldosterone to exert its salt-retaining activity. On the other hand it is obvious that a complete absence of 21hydroxylation could prevent the formation of aldosterone.

Studies of actual aldosterone excretion have been made in only a few laboratories and there is a discrepancy in the findings (Prader, Spahr and 


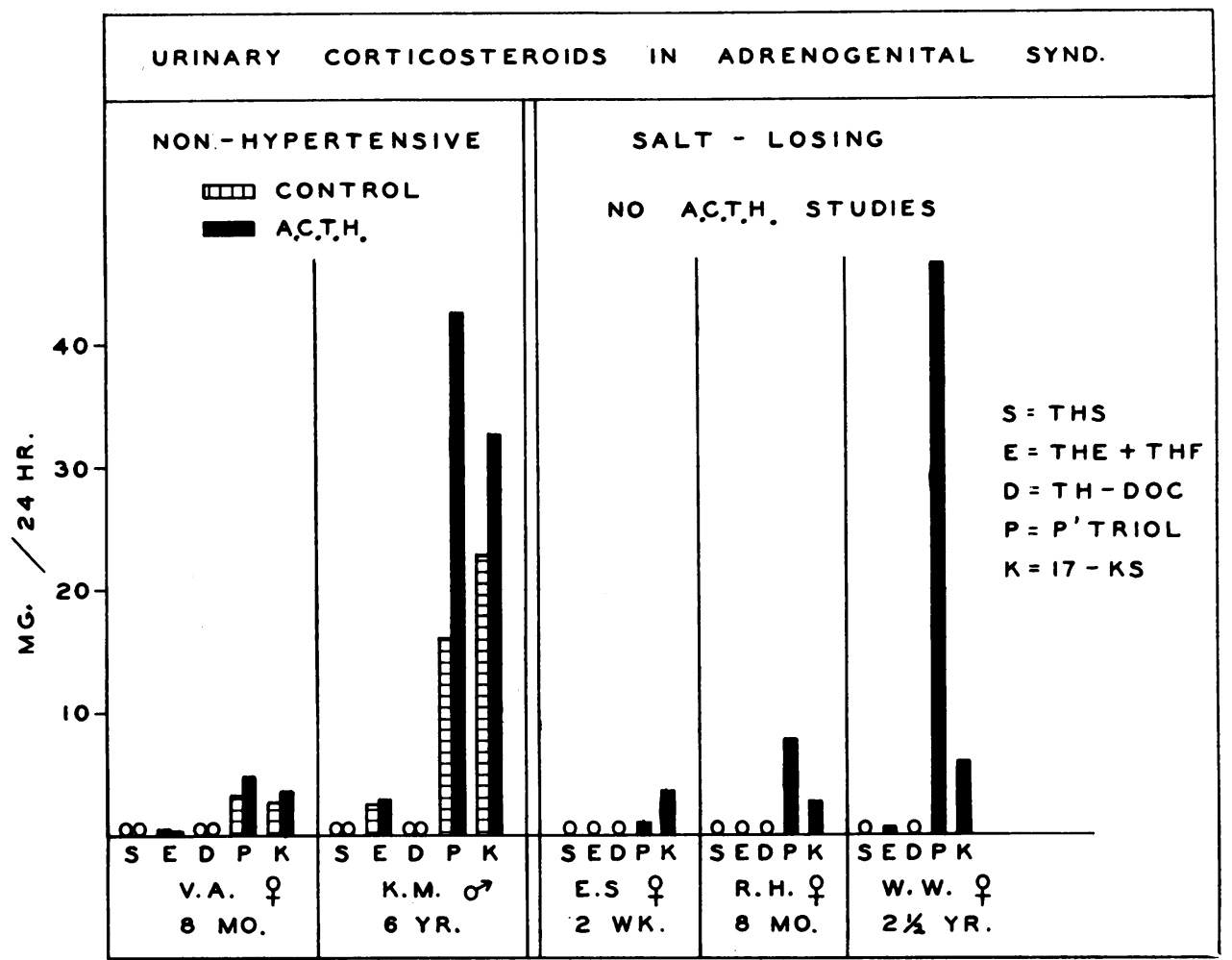

Fig. 9.-Variations of urinary steroidal patterns in cases of simple virilizing and Na-losing adrenal hyperplasia (from Green et al., 1960).

Neher, 1955; Blizzard, Liddle, Migeon and Wilkins, 1959; Rosemberg, Dufault, Bloch, Budnitz, Butler and Brem, 1960). Aldosterone determinations made by Grant Liddle (Blizzard et al., 1959) on our patients showed low levels in the salt losers and higher levels than normal in patients with simple virilizing adrenal hyperplasia (Fig. 10). During five-day periods of sodium deprivation, the salt losers were unable to respond with increased aldosterone and could not conserve sodium (Fig. 11). It is our opinion that patients with both the simple virilizing and the salt-losing types may have impaired ability to reabsorb sodium and that the former compensate for this with overproduction of aldosterone while the latter cannot.

\section{Genetic Studies}

In 1956, Childs and co-workers (Childs, Grumbach and Van Wyk, 1956) reported genetic studies made on our patients. There were 76 affected individuals among 181 sibs in 56 families. There were no affected parents, grandparents, uncles, aunts or cousins. There was only one family in which there was consanguinity, the parents being first cousins. As stated previously, Childs felt there was no true difference in the sex ratio of

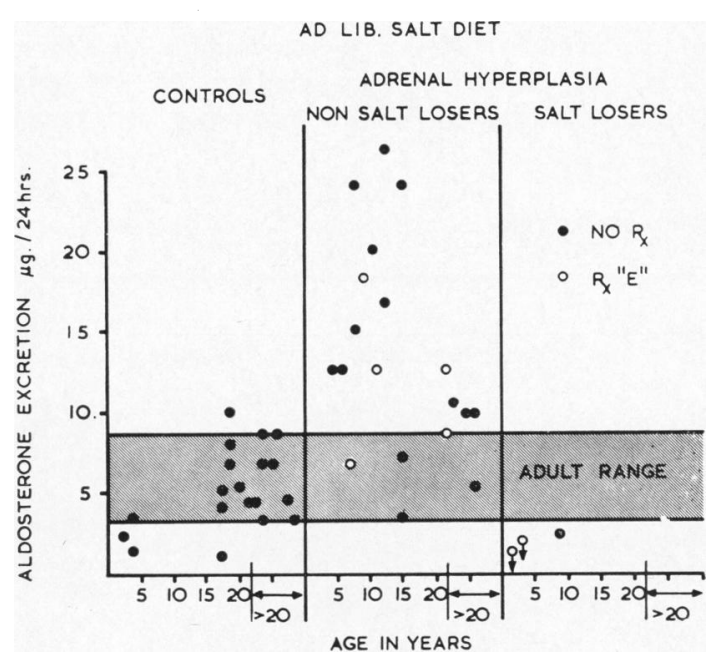

FIG. 10.-Aldosterone excretion in salt-losing and non-salt-losing types of virilizing adrenal hyperplasia (from Blizzard et al., 1959). 


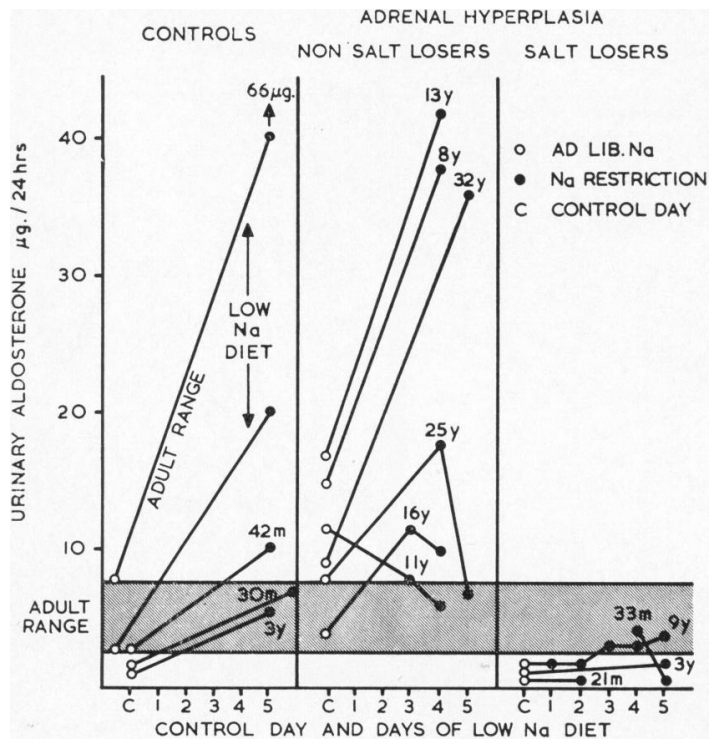

FIG. 11.-Effects of sodium deprivation on aldosterone excretion in salt-losing and non-salt-losing patients with adrenal hyperplasia (from Blizzard et al., 1959). $y=$ age in years. Shaded area represents normal adult range of aldosterone excretion when adults are on ad lib. sodium.

affected patients, the apparent difference being due to the greater difficulty in recognizing the disorder in males. There was no evidence of deleterious effects on gestation or labour in the mothers of the patients nor any evidence of maternal influence on the disorder. He came to the conclusion that the disorder was due to an autosomal, recessive gene which manifests itself only in the homozygote.

It would be most valuable to know the frequency of the gene in the population and to be able to detect the heterozygotous carriers of the gene. Childs, making the rather grandiose assumption

TABLE 6

CALCULATION OF CHANCES OF OCCURRENCE OF HOMOZYGOUS AFFECTED OFFSPRING

$\mathrm{Aa}+\mathrm{Aa}=1: 4$

Chance Marriage in General Population Mother Father

$$
\begin{aligned}
& \frac{\mathrm{Aa}}{100} \times \frac{\mathrm{Aa}}{100}=\frac{1}{10,000} \times \frac{1}{4}=\frac{\mathrm{AA}}{40,000} \\
& \frac{\mathrm{Aa}}{50} \times \frac{\mathrm{Aa}}{50}=\frac{1}{2,500} \times \frac{1}{4}=\frac{\mathrm{AA}}{10,000}
\end{aligned}
$$

Marriage of Homozygotous patient

$$
\begin{aligned}
& A A+\frac{A a}{100}=\frac{1}{100} \times \frac{1}{2}=\frac{A A}{200} \\
& A A+\frac{A a}{50}=\frac{1}{50} \times \frac{1}{2}=\frac{A A}{100}
\end{aligned}
$$

that all patients with the disorder born in Maryland after 1939 came to my own clinic, estimated that the disease occurred once per 67,000 births and calculated that the incidence of heterozygotes was one per 128 individuals of the general population. We suspect now that the incidence of the trait may be between 1:50 and 1:100. Prader (1958) of Zurich estimates that there is one adrenogenital patient among every 5,000 births in Switzerland, giving an incidence of the gene of $1: 37.5$ in the general population.

Before the introduction of cortisone therapy patients were practically always sterile; with treatment, however, ovulation and spermatogenesis occur. Before we understood the genetics of the disorder, having observed the high incidence of affected sibs in some families, we advised our treated patients not to produce children. If the disease is manifested only in homozygotes, however, the treated patients have only a 1:100 to $1: 200$ chance of producing affected offspring as shown in Table 6. If a marriage with a heterozygotous carrier could be avoided, there would be no risk at all.

If the fathers and mothers of the affected individuals are heterozygotous carriers, they might be expected to have a minor enzymatic defect which might be demonstrable. Since the defect in the homozygotous patient is well demonstrated by the degree to which urinary pregnanetriol increases after the administration of A.C.T.H., Childs et al. (1956) applied this test to the study of 10 mothers and 10 fathers of our patients. With the exception of one father and one pregnant mother, the increment of pregnanetriol ranged from 0.4 to $3.7 \mathrm{mg}$./day, compared with 0.0 to $4.4 \mathrm{mg}$./day in random controls. The difference of the means was barely significant. It is of interest that in one father the pregnanetriol rose $41 \cdot 3 \mathrm{mg}$.

Recently Jailer (J. W. Jailer, personal communication) and later Cleveland and Migeon (1960) studied the effects of introducing an 11-hydroxylation block with the chemical SU-4885 in patients with simple virilizing adrenal hyperplasia who have the 21-hydroxylation defect. This causes the output of pregnanetriol and its precursor, 17-OH-pregnanolone, to rise as high as 100 to $260 \mathrm{mg}$./day compared to the usual output of $40-80 \mathrm{mg}$./day after stimulation with A.C.T.H. As shown in Fig. 12, this is due to the fact that with the SU-4885 block the 11-keto-pregnanetriol (not measured by the usual methods) cannot be formed and all of the precursors appear as pregnanetriol and 17-hydroxypregnanolone. The ratio of these pregnane compounds to the Porter-Silber chromogens can be used 


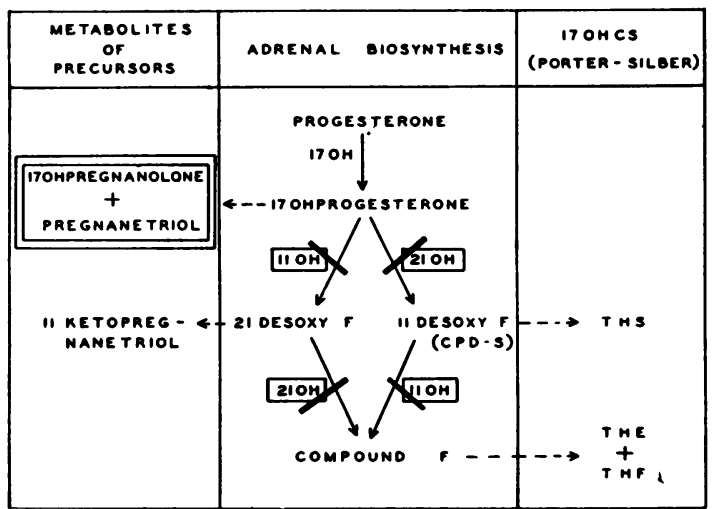

FIG. 12.-Effect of SU-4885 (11-hydroxylase block) in patients with simple virilizing adrenal hyperplasia (from Cleveland and Migeon, 1960).

Note that 17-OH-pregnanolone and pregnanetriol are greatly increased, while 11-ketopregnanetriol, THS, THE and THF are decreased.

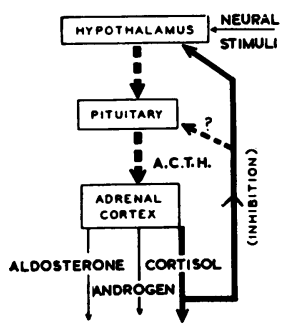

NORMAL

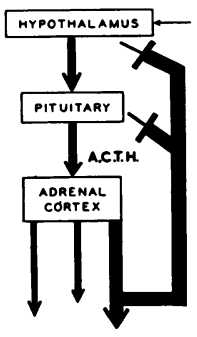

CUSHING'S SYMDAOME

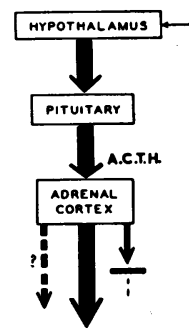

ADRENOGENITAL
FIG. 13.-The hypothalamic-pituitary-adrenal axis and the probable defects in Cushing's syndrome and the adrenogenital syndrome. Adrenal activity is regulated by the plasma level of cortisol through the A.C.T.H. secreting mechanism of the hypothalamus and pituitary. Normally when the cortisol concentration rises above physiological requirements A.C.T.H. secretion is inhibited. This intermittent inhibition may account for the normal diurnal fluctuations.

In Cushing's syndrome high levels of cortisol do not suppress the A.C.T.H. secretion as they normally do. Accordingly there is a constant, though not greatly elevated, secretion of A.C.T.H. and diurnal variations do not occur. In the adrenogenital syndrome there is a defect in the synthesis of cortisol and secretion of androgenic precursors. To compensate for this there is greatly increased secretion of A.C.T.H.

TABLE 7

RATIO OF PREGNANES/PORTER-SILBERS IN ADRENOGENITAL PATIENTS AND THEIR PARENTS

\begin{tabular}{c|c|c}
\hline \multicolumn{1}{c|}{ Subjects } & Average Ratio & Range \\
\hline Five patients & $\frac{145}{10 \cdot 4}=14$ & $5.9-26$ \\
Six normal & $\frac{2 \cdot 6}{21 \cdot 1}=0.13$ & $0.10-0.18$ \\
Nine parents & $\frac{3 \cdot 3}{28.0}=0.13$ & $0.01-0.20$ \\
\hline
\end{tabular}

The higher the ratio the greater is the 21-hydroxylase defect. as a measure of the degree of 21-hydroxylation defect. Cleveland and Migeon carried out the SU-4885 block in 10 parents, five patients and six adult controls. As shown in Table 7, nine of the parents did not respond differently from normal controls. It is of interest, however, that one father had the abnormally high ratio of six, which is in the range of the affected patients. We discovered later that this is the same father who responded with abnormally high pregnanetriol when studied under A.C.T.H. stimulation by Childs et al. We wonder whether he might be a homozygote, but have no evidence of this. We are still left without any method for detecting most of the heterozygotes.

In conclusion, I would like to call attention again to the diagram (Fig. 13) shown as Fig. 6 in Part 1, which summarizes almost everything which I have said in the last two days concerning our present theories on the pathogenesis of Cushing's syndrome and the adrenogenital syndrome.

\section{REFERENCES}

Bartter, F. C., Albright, F., Forbes, A. P., Leaf, A., Dempsey, F. and Carroll, E. (1951). The effects of adrenocorticotropic hormone and; cortisone in the adrenogenital syndrome associated with congenital adrenal hyperplasia : an attempt to explain and correct its disordered hormonal pattern. J. clin. Invest., 30, 237.

Blizzard, R. M., Liddle, G. W., Migeon, C. J. and Wilkins, L. (1959). Aldosterone secretion in virilizing adrenal hyperplasia. ibid., 38, 1442.

Bongiovanni, A. M. (1961). Unusual steroid pattern in congenital adrenal hyperplasia: Deficiency of 3- $\beta$-hydroxy-dehydrogenase. J. clin. Endocr., 21, 860.

- and Eberlein, W. R. (1958). Defective steroidal biogenesis in congenital adrenal hyperplasia. Pediatrics, 21, 661.

,-- and Cara, J. (1954). Studies on the metabolism of adrenal steroids in the adrenogenital syndrome. J. clin. Endocr., 14, 409.

Childs, B. (1960). Genetics and metabolism. Pediatrics, 25, 565.

-_, Grumbach, M. M. and Van Wyk, J. J. (1956). Virilizing adrenal hyperplasia: a genetic and hormonal study. J. clin. Invest., 35, 213.

Cleveland, W. W. and Migeon, C. J. (1960). Response to an 11hydroxylase inhibitor (SU-4885) in patients with adrenal hyperplasia and their parents (Abstract). Amer. J. Dis. Child., $100,473$.

Eberlein, W. R. and Bongiovanni, A. M. (1955). Congenital adrenal hyperplasia with hypertension: unusual steroid pattern in blood and urine. J. clin. Endocr., 15, 1531.

- _ (1960). Pathophysiology of congenital adrenal hyperplasia. Metabolism, 9, 326.

Green, O. C., Migeon, C. J. and Wilkins, L. (1960). Urinary steroids in the hypertensive form of congenital adrenal hyperplasia. J. clin. Endocr., 20, 929.

Jailer, J. W. (1953). Virilism. Bull. N.Y. Acad. Med., 29, 377.

Prader, A. (1958). Die Häufigkeit des kongenitalen adrenogenitalen Syndroms. Helv. paediat. Acta, 13, 426.

- Spahr, A. and Neher, R. (1955). Erhöhte aldosteronausscheidung beim Kongenitalen adrenogenitalen Syndrom. Schweiz. med. Wschr., 85, 1085.

Rosemberg, E., Dufault, F. X., Jr., Bloch, E., Budnitz, E., Butler, P. and Brem, J. (1960). The effects of progressive reduction of sodium intake on adrenal steroid excretion and electrolyte balance in a case of congenital adrenal hyperplasia of the saltlosing type. J. clin. Endocr., 20, 214.

Sydnor, K. L., Kelley, V. C., Raile, R. B., Ely, R. S. and Sayers, G. (1953). Blood adrenocorticotropin in children with congenital adrenal hyperplasia. Proc. Soc. exp. Biol. (N.Y.), 82, 695.

Wilkins, L. (1961). Diagnosis and treatment of congenital virilizing adrenal hyperplasia. Postgrad. Med., 29, 31.

, Gardner, L. I., Crigler, J. F., Jr., Silverman, S. H. and Migeon, C. J. (1952). Further studies on the treatment of congenital adrenal hyperplasia with cortisone. J. clin. Endocr., 12, 257. 